\title{
Global assessment of deforestation related to tobacco farming
}

\author{
Helmut J Geist
}

\begin{abstract}
Objectives-To assess the global amount of forest and woodland consumed annually for curing tobacco between 1990 and 1995; to estimate tobacco's share in total deforestation; to rank tobaccogrowing countries by the degree of impact of tobacco deforestation; and to indicate environmental criticality emerging from tobacco's impact on forest resources.

Design-Production of country-specific estimates of forests/woodlands needed and depleted on the basis of growing stock/increment of woody biomass involved and wood consumption of tobacco. Comparison of results with secondary statistics on forest cover, deforestation, and population development.

Results-An estimated 200000 ha of forests/woodlands are removed by tobacco farming each year. Deforestation mainly occurs in the developing world, amounting to $1.7 \%$ of global net losses of forest cover or $4.6 \%$ of total national deforestation. Environmental criticality exists or is emerging in 35 countries with an estimated serious, high, and medium degree of tobacco-related deforestation, mainly in southern Africa, middle east, south, and east Asia, South America, and the Caribbean.

Conclusion-The hypothesis that deforestation from tobacco production does not have a significant negative effect has to be challenged. For empirical validation, the globally significant pattern of estimated tobacco-related environmental damage ought to be included in international research agendas on global environmental change, to become an integral and rational part of tobacco control policy.

(Tobacco Control 1999;8:18-28)
\end{abstract}

Keywords: deforestation, tobacco farming

\section{Introduction}

Since the late 1970s, growing concerns have been expressed about the "energy" or "fuelwood" crisis caused by tobacco production, ${ }^{2}$ with emphasis being placed on deforestation caused by the outstanding rate of soil nutrient depletion and considerable usage of wood. Tobacco production is considered to pose "a particularly difficult dilemma for development," as it generates a range of employment, income, foreign exchange, and other cash-contributing effects, while "the damage to public health and to the environment in the long term appears substantially to outweigh the benefits." ${ }^{2}$ Very approximate data for mid-1980 suggested that Virginia (flue-cured) tobacco consumes between 82.5 and 175 million cubic metres of roundwood harvested worldwide each year for curing, and that this translates into the equivalent of 1.2-2.5 million hectares of open forests or woodlands removed annually. ${ }^{23}$ Since then, no other estimations have been made to quantify the problem.

The Bellagio statement on tobacco and sustainable development concluded that, in the developing world, "tobacco poses a major challenge, not just to health, but also to . . . environmental sustainability." Similarly, the United Nations Food and Agriculture Organisation (FAO) has noted-without providing data-the consequences of tobacco-related deforestation in the form of fuelwood shortages among rural populations in the developing world. ${ }^{5}$

In contrast, reports commissioned by the tobacco industry have sought to repudiate previous acknowledgement of the problem by playing down the issue: "Deforestation associated with tobacco curing cannot currently be considered a significant negative externality." ${ }^{7}$ This statement contrasts with the conclusions of a mid-1980s consultancy study by Fraser ${ }^{8}$ on the use of wood in tobacco production and its ecological implications, which until recently has been regarded as the definitive study. On the basis of wood consumption data, population statistics, and forest density figures, this study stated: "It is important to note that a high proportion of the tobacco growing areas in developing countries lie within parts of the world identified [by the] FAO as being in wood deficit or prospective wood deficit situations." As to the situation in the developing world (excluding China) (figure 1), Fraser noted that "the area of all types of forest in most African and Asian countries is now below the level at which it is capable of meeting the current and future fuelwood demand on a sustainable basis. This means that accelerating deforestation can be expected, with potentially serious ecological consequences." ${ }^{8}$ Although deforestation was not explicitly calculated, by considering tobacco production and forest availability Fraser concluded: "The figures 


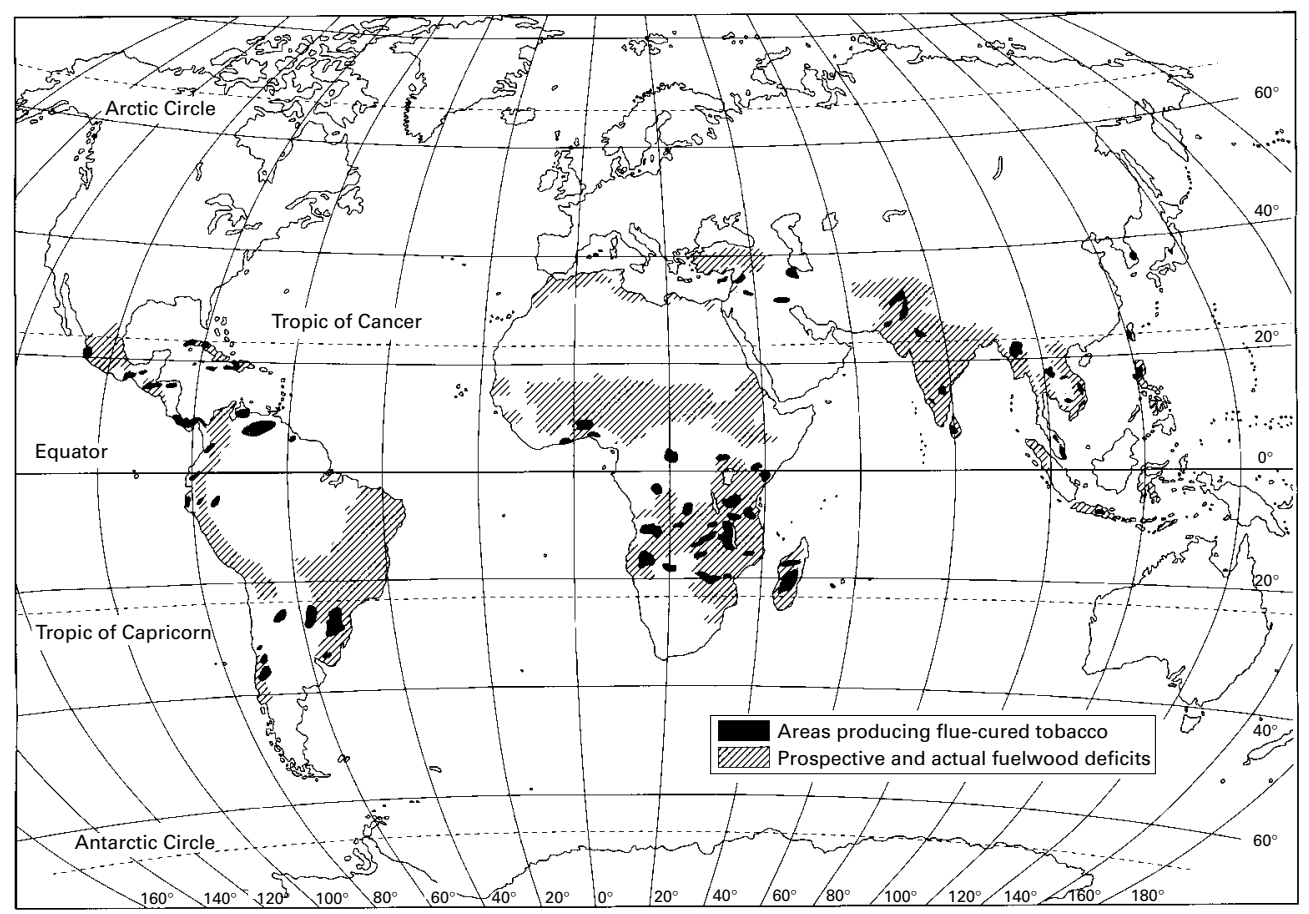

Figure 1 In many countries where flue-cured tobacco is grown, fuelwood demand is not sustainable. (After Fraser. ${ }^{8}$ )

suggest that most Asian tobacco-growing countries, and selected African countries have general fuelwood shortages and are therefore likely to experience accelerating deforestation." 8

The dataset on wood consumption has recently been updated with data from selected developing countries for mid-1990. ${ }^{9}$ Again, deforestation was not explicitly calculated, while the concept of a change in the economics of fuel choice has started to pervade much of the industry's rhetoric. The 1997 International Tobacco Grower's Association report stated: "Developing countries ... will continue to use wood as a curing fuel because no cost-effective alternative has emerged. Through the establishment of renewable, energy-efficient and regularly harvestable sources in managed tree plantations, they will, however, stabilise the impact they make on the deforestation question."."

The objective of this paper is to quantify the issue of deforestation related to tobacco farming on a global scale. Claims that tobacco-caused deforestation is insignificant will be challenged. In the calculation of estimates of deforested areas due to tobacco production, use has been made of all recently available data on wood consumption by tobacco. ${ }^{10}$ The paper starts by outlining the underlying causes or driving forces of deforestation related to tobacco farming.

\section{Determinants of tobacco-related deforestation}

Among the underlying causes of tobaccorelated deforestation are (a) the usage of wood in the farm-based process of curing the crop, that is, drying the leaves, and (b) the global shift of production into low-cost producer countries of the developing world which typically have fragile natural environments. Not considered here, but relevant especially under tropical conditions, are the agricultural practices of topping and desuckering, that is, designing the tobacco plant as a consumer product that will have a high nicotine content. The result is a uniquely high uptake of all macronutrients from the soil, and tobacco's regular need for fertile (virgin) soils which are often provided by land clearances involving deforestation. ${ }^{211}$

Tobacco farming requires substantial amounts of wood for a variety of purposes, such as curing, and poles and sticks for barn construction. On the basis of a compilation and standardisation of national data on wood usage, the annual global wood usage of tobacco has been calculated as a mean 19.9 stacked cubic metre per tonne of tobacco (median = 18.9$, mode $=1.0) .{ }^{10}$ To varying degrees, wood usage was found to be widespread in nearly all developing countries. Expressed in percentages of global tobacco production in the first half of the 1990s, major consumers of wood were dark air/sun-cured tobaccos (15\%), burley (12\%), flue-cured $(12 \%)$, and oriental tobacco $(9 \%)$, with fire-cured and dark, as well as light air-cured tobaccos being minor consumers (around $1 \%$ each).

Thus, around half of global tobacco production (3.8 million tonnes) relied upon inputs of wood totalling 26.6 million stacked cubic metres, or 11.4 million tonnes of solid wood. ${ }^{10}$ Although flue-cured tobacco accounts for only $12 \%$ of the global produce using wood, it makes up for $60 \%$ of solid wood consumed, with firewood uses being the major part (table 1).

Since the mid-1960s, a global shift of tobacco production has occurred which has several socioecological consequences. Compared with 1700 , when nearly the entire world 
Table 1 Global assessment of annual deforestation caused by wood use in tobacco farming, 1991-1995

\begin{tabular}{|c|c|c|c|c|c|c|c|c|c|c|c|}
\hline \multicolumn{3}{|c|}{ Flue-cured tobacco } & \multicolumn{3}{|c|}{ Fire-cured tobacco } & \multirow{2}{*}{$\frac{\text { Bur }}{\text { Poles }}$} & \multirow{2}{*}{$\begin{array}{l}\text { Das } \\
\text { Poles }\end{array}$} & \multirow{2}{*}{$\begin{array}{l}\text { Ori } \\
\text { Poles }\end{array}$} & \multirow{2}{*}{$\begin{array}{l}\text { Dac } \\
\text { Poles }\end{array}$} & \multirow{2}{*}{$\begin{array}{l}\text { Lac } \\
\text { Poles }\end{array}$} & \multirow[t]{2}{*}{ All } \\
\hline Fuel & Poles & Total & Fuel & Poles & Total & & & & & & \\
\hline \multicolumn{12}{|c|}{ (1) Total annual global tobacco production ('000 tonnes dry weight) $(\%)^{19}$} \\
\hline & $\begin{array}{l}4627 \\
(61.1) \\
(n=82)\end{array}$ & & & $\begin{array}{l}54 \\
(0.7) \\
(\mathrm{n}=17)\end{array}$ & & $\begin{array}{l}893 \\
(11.9) \\
(n=65)\end{array}$ & $\begin{array}{l}1094 \\
(14.6) \\
(n=56)\end{array}$ & $\begin{array}{l}651 \\
(8.7) \\
(n=37)\end{array}$ & $\begin{array}{l}114 \\
(1.5) \\
(n=26)\end{array}$ & $\begin{array}{l}77 \\
(1.0) \\
(\mathrm{n}=29)\end{array}$ & $\begin{array}{l}7510 \\
(100) \\
(n=118)\end{array}$ \\
\hline \multicolumn{12}{|c|}{ (2) Tobacco production using wood ('000 tonnes dry weight) ( $\%$ of global tobacco production $)^{10}$} \\
\hline$(n=56)$ & $\begin{array}{l}895 \\
(11.9) \\
(n=54)\end{array}$ & $(\mathrm{n}=56)$ & $(\mathrm{n}=17)$ & $\begin{array}{l}54 \\
(0.7) \\
(\mathrm{n}=17)\end{array}$ & $(n=17)$ & $\begin{array}{l}893 \\
(11.9) \\
(n=65)\end{array}$ & $\begin{array}{l}1094 \\
(14.6) \\
(n=56)\end{array}$ & $\begin{array}{l}651 \\
(8.7) \\
(n=37)\end{array}$ & $\begin{array}{l}114 \\
(1.5) \\
(n=26)\end{array}$ & $\begin{array}{l}77 \\
(1.0) \\
(\mathrm{n}=29)\end{array}$ & $\begin{array}{l}3778 \\
(50.3) \\
(n=116)\end{array}$ \\
\hline \multicolumn{12}{|c|}{ (3) Total annual solid wood required for tobacco production ('000 tonnes) $(\%)^{10}$} \\
\hline $\begin{array}{l}6810 \\
(59.5)\end{array}$ & $\begin{array}{l}38 \\
(0.3)\end{array}$ & $\begin{array}{l}6849 \\
(59.8)\end{array}$ & $\begin{array}{l}560 \\
(4.9)\end{array}$ & $\begin{array}{l}12 \\
(0.1)\end{array}$ & $\begin{array}{l}571 \\
(5.0)\end{array}$ & $\begin{array}{l}987 \\
(8.6)\end{array}$ & $\begin{array}{l}2030 \\
(17.7)\end{array}$ & $\begin{array}{l}696 \\
(6.1)\end{array}$ & $\begin{array}{l}181 \\
(1.6)\end{array}$ & $\begin{array}{l}124 \\
(1.1)\end{array}$ & $\begin{array}{l}11437 \\
(100)\end{array}$ \\
\hline \multicolumn{12}{|c|}{ (4) Additional (deficit) wood required annually for tobacco production ('000 tonnes) ${ }^{10}$} \\
\hline 3011 & 17 & 3028 & 365 & 7 & 373 & 575 & 1150 & 404 & 102 & 67 & 5698 \\
\hline \multicolumn{12}{|c|}{ As \% of total (5698) } \\
\hline $\begin{array}{l}52.8 \\
(\mathrm{n}=54)\end{array}$ & $\begin{array}{l}0.3 \\
(n=52)\end{array}$ & $\begin{array}{l}(53.1) \\
(n=54)\end{array}$ & $\begin{array}{l}6.4 \\
(n=15)\end{array}$ & $\begin{array}{l}0.1 \\
(n=15)\end{array}$ & $\begin{array}{l}(6.5) \\
(n=15)\end{array}$ & $\begin{array}{l}10.1 \\
(n=63)\end{array}$ & $\begin{array}{l}20.2 \\
(n=55)\end{array}$ & $\begin{array}{l}7.1 \\
(n=37)\end{array}$ & $\begin{array}{l}1.8 \\
(n=26)\end{array}$ & $\begin{array}{l}1.2 \\
(\mathrm{n}=28)\end{array}$ & $\begin{array}{l}100 \\
(n=114)\end{array}$ \\
\hline \multicolumn{12}{|c|}{$\begin{array}{l}\text { (5) Sustained-yield area of woody biomass needed annually to provide (4) ('000 ha*) } \\
\text { Natural (medium) woody biomass potential, mostly woodlands and dry forests ('000 }\end{array}$} \\
\hline 6022 & 34 & 6056 & 730 & 15 & 745 & 1149 & 2299 & 807 & 204 & 134 & 11396 \\
\hline \multicolumn{12}{|c|}{ Plantation forest ('000 ha ${ }^{\star}$ ) } \\
\hline \multicolumn{12}{|c|}{ (6) Equivalent area of natural woody biomass deforested ('000 ha } \\
\hline 111 & $<1$ & 112 & 14 & $<1$ & 14 & 21 & 43 & 15 & 4 & 2 & 211 \\
\hline
\end{tabular}

Bur = Burley tobacco; Dac $=$ Dark air-cured $($ cigar $)$ tobacco $;$ Das = Dark air/sun-cured tobaccos; Lac $=$ Light air-cured tobaccos; Ori $=$ Oriental tobacco.

$\star 1$ Hectare $=0.01 \mathrm{~km}^{2} . \mathrm{n}=$ Number of tobacco-growing countries for which data were available.

production of tobacco was concentrated in Brazil, parts of the Caribbean, and in the Chesapeake colonies of northern America, with the breakdown of colonial rule from the mid-19th century, tobacco farming spread nearly all over the world. ${ }^{12-14}$ At present, the quantities entering world trade originate mostly from zones of the developing world where frost-free days, a sufficiently long dry season (allowing for harvesting and curing the crop), and low-cost conditions of production are optimal. By the end of the 1990s, around four-fifths of more than 120 developing countries or the equivalent of around $90 \%$ of all global land under tobacco ${ }^{15}$ is now located in developing nations. In general, the natural environments where tobacco is commonly grown fall more in highlands than lowlands and more in dryland than humid ecosystems (semi-arid to semi-humid climates). ${ }^{12} 13$

The general fragility of ecosystems under such climates suggests the notion that tobacco farming mostly occurs in environmentally threatened areas or regions at risk. Although forest-covered highlands constitute critical environmental zones, in that watershed management is essential to prevent large-scale, offsite effects, dryland areas are "are among the world's most fragile ecosystems, and are made more so by periodic droughts and the risk of desertification." ${ }^{16}$ Drylands cover 30\% of the world's land area and are inhabited by a large proportion of people who are among the world's poorest (and thus particularly responsive to growing a cash-generating crop such as tobacco). An estimated $70 \%$ of the world's drylands are affected by desertification due to land degradation caused by climate and human activities. The major causes of humaninduced land degradation are considered to be large-scale deforestation, mainly for conversion to agricultural uses, and overexploitation of forests and woodlands through fuelwood collection. ${ }^{16}{ }^{17}$ Relatively dry as well as upland areas are extremely prone to deforestation, as they provide more favourable conditions for agriculture than humid lowlands or rainforest zones. The most recent tropical trend to be observed is that "deforestation [has] progressed more in the uplands than in the lowlands," 17 and that areas under dry forests are about to turn into "the most endangered major tropical ecosystem." 18

From the social driving forces of tobacco farming outlined, a pattern of emerging criticality could be assumed. Indicative evidence is provided by the following global indicators of tobacco versus arable land development.

- The bulk of land under tobacco $(63 \%)$ is located in low-income countries of the (sub)tropical zones, and the mean global rate of tobacco's area expansion from 1982 to 1996 ( $0.4 \%$ each year) has been exceeded in these zones ( $2 \%$ per year). ${ }^{15}$

- Although during the same period of time, arable land expanded at a rate six times higher than tobacco (2.4\% each year), in more than 20 developing countries, most of them in the developing world and holding more than half of global production, land under tobacco increased at even higher rates - up to 10 times in Pakistan, Philippines, China, Zimbabwe, and Malawi, for example, and in some cases even more (such as in Zambia and Uganda). ${ }^{15}$

- Although the present global share of land under tobacco in all arable land is only $0.6 \%$, it is far above average in major tobacco-growing areas of the developing world, such as subtropical east Asia (1.5\%) and tropical southern Africa (2.3\%). ${ }^{15}$

- Less than half of the land under tobacco $(42 \%)$ is grown with naturally cured varieties, using natural variations in temperature and humidity to dry up the 
leaves through air and sun-curing, whereas artificially cured varieties - those using heat from external sources such as wood and coal (fire/flue-curing) - account for the majority of global land under tobacco $(58 \%)$, and more so in the developing world (73\%). ${ }^{10} 19$

\section{Research design}

ASSUMPTIONS ON WOOD USAGE, DEFORESTATION, AND AFFORESTATION

Major assumptions used to calculate tobacco-induced deforestation are provided here. First, unless specified as plantation forests, wood is assumed to be commonly taken from native forests and woodlands, being regarded as "free goods", requiring no payment to be made towards the cost of replacement. ${ }^{8}$ Second, only where shortages have developed, does the market price of wood rise to a level where investment in plantation forests becomes attractive. ${ }^{8}$ Third, investment in plantation forestry will not take place on a sufficient scale "until most of the natural forest has been destroyed." ${ }^{8}$ Fourth, the percentage of tobacco farmers known to have no private woodfuel plantings ( $58 \%$ as a global average $)^{10}$ is used as the proportion of tobacco produce using wood taken from native forests and woodlands. Fifth, although wood usage and deforestation occurs in a few tobacco-growing countries of the developed world (as defined by the $\mathrm{FAO}^{16}$ ) - that is, Romania, Japan, and South Africa-no wood was assumed to be taken from natural vegetation in developed nations.

DEPLETION OF GROWING STOCK

Commonly expressed in solid measures, the growing stock (GS) of woody biomass, which is normally the commercially harvestable part of the tree, gives the (solid) volume of wood standing on a given area such as one hectare $\left(0.01 \mathrm{~km}^{2}\right)$. "If more than the increment is cut, some of the growing stock is removed and increment in the following years will be reduced. If this 'overcutting' persists, the rate of decrease of the growing stock will accelerate, and the forest will eventually be totally destroyed." ${ }^{8}$ While this process could be called forest degradation, the focus in this paper is on deforestation, which means no persistent overcutting (merely reduction of increment), but complete removal of the natural woody biomass (depletion of growing stock).

Three major GS specifications were available for a low, medium, and high woody biomass potential representing all major ecosystems of the African continent. ${ }^{20}$ The (median) value of 27 (air-dry) tonnes per hectare $(\mathrm{t} / \mathrm{ha})$ of medium woody biomass was used, since this type of vegetation is most common to the natural environments where tobacco is grown. Other GS rates represent "low woody biomass potential", that is, wooded grasslands, shrubland, bushland and thicket (averaging $8 \mathrm{t} / \mathrm{ha}$ ), and "high woody biomass potential"-humid tropical forests, evergreen and montane forests, coastal and gallery forests, swamp forests, and mangrove (122 t/ha ). ${ }^{20}$ The GS rate selected represents the average value of 16 different land-cover classes containing (a) "low woody biomass mosaics", (b) any type of woodland, that is, open, seasonal, dry, and moist woodlands, and (c) "high woody biomass mosaics", that is, evergreen woodland mosaics, cultivation and forest/woodland mosaics, cultivation and forest regrowth, as well as highland cultivation mosaics. ${ }^{20}$ The African value used is assumed to resemble comparable growing environments on other continents.

MEAN ANNUAL INCREMENT

The term mean annual increment (MAI) means the annual increase in the aggregate volume of trees, commonly expressed in solid volume per hectare. It is often used to indicate the yield, since it represents the long-term sustainable quantity of wood which can be harvested. ${ }^{8}$ The average value of 0.5 (air-dry) t/ha per year as a median of 16 land cover classes ${ }^{20}$ is taken to assess the (hypothetical) sustained-yield area of natural medium woody biomass required to provide wood. For plantation forests, two different MAI values are used to assess (hypothetical) plantation establishment. The MAI of temperate plantations is normally in the range of $2-12 \mathrm{~m}^{3} /$ ha per year (the mean of $7 \mathrm{~m}^{3} / \mathrm{ha}$ is taken), and tropical plantations normally give an MAI in the range of $6-24 \mathrm{~m}^{3} /$ ha per year (mean $\left.=15 \mathrm{~m}^{3} / \mathrm{ha}\right)$.

CONVERSION FACTORS USED

A stack of wood is one metre long by one metre wide by one metre high, giving a total volume of one (stacked) cubic metre $\left(\mathrm{stm}^{3}\right)$. Due to irregular gaps and air spaces, only approximately $60-70 \%$ of the volume is made up of solid wood, so that the weight of wood in one stack will range from approximately 250-600 kg. This translates into a mean stacking factor of $425(\mathrm{~kg})$ or 0.43 (tonnes). ${ }^{8} \mathrm{An}$ equivalent ratio of 2.33 tonnes could thus be used to convert solid wood into stackwood. For comparison, and to give a rough indication of the order of magnitude involved, one stacked cubic metre of fuelwood provides heating and cooking for one person for a year, brews 400 litres of beer, smokes one tonne of fish, cures $50 \mathrm{~kg}$ of tobacco, or fires 3000 bricks, being a third of what is needed to build a standard rural house. ${ }^{1021}$

SIX STEPS TOWARDS ESTIMATING DEFORESTATION Assessing tobacco-specific deforestation consists of six major steps (table 1). The main objective is to translate the annual amount of solid wood required (in tonnes, t), but not supplied from private sources (additional or "deficit" wood), into the equivalent area of woody biomass needed (in hectares) and either managed on a sustainable basis (using MAI) or deforested (using GS).

\section{(1) Total annual world tobacco production}

To be comparable with the most recent annual 1990-95 FAO data on global forest-cover change by country, the annual production of tobacco is specified as a five-year average for 1991-1995 by variety grown. ${ }^{16}$ As different 
tobaccos require different uses of wood, tobacco data of seven crop varietes for about 120 developing countries are used. ${ }^{19}$

\section{(2) Annual tobacco production using wood}

From crop-specific wood requirements and national wood consumption data, the share and amount of global tobacco produce making usage of wood is derived. ${ }^{10}$

\section{(3) Annual solid wood required for tobacco} The national usage of wood on a yearly basis was calculated in stackwood and subsequently converted into solid measures, to have standardised rates compared with the specification of GS and MAI. The breakdown by usages of wood for fuel and poles allows for a crop-specific and purpose-specific assessment.

(4) Additional annual (deficit) wood required for tobacco

Using approximate values of the degree of selfsufficiency in wood obtained from farmers' private sources, the share and amount of solid wood originating from open, accessible (common) land and natural forests was derived. ${ }^{10}$ The national percentage of tobacco farmers who are self-sufficient in wood (for example, $82 \%$ of Brazilian and $7 \%$ of Tanzanian flue-cured tobacco growers having their own woodfuel plantings ${ }^{10}$ ) was converted into the equivalent of deficit wood needed for all tobaccos and taken from common land $-18 \%$ and $93 \%$ in the case of Brazil and Tanzania, respectively. For 15 developing countries, estimates of self-sufficiency exist in the range of $5 \%$ (Poland) to $100 \%$ (Kenya, Congo/Zaire), whereas the mean of $42 \%$ was applied in all other cases. ${ }^{10}$

(5) Sustained-yield area of woody biomass needed to provide (4)

Using the MAI values as specified, the equivalent area of woody biomass needed and assumed to be harvested on a sustained-yield basis was calculated.

\section{(6) Equivalent area of natural woody biomass deforested}

Using GS values as specified for a medium woody biomass potential (forest, woodlands, vegetational mosaics), the wooded area needed and not harvested on a sustained-yield basis, but completely removed instead (deforested), was calculated.

ASSESSING TOBACCO'S PART IN TOTAL

DEFORESTATION

To provide a rough indication of the order of magnitude involved, national estimation values of tobacco-specific deforestation were compared with national deforestation FAO data. ${ }^{16}$ In doing this, implicit use had to be made of the FAO concept of forest cover, that is, ecosystems with a minimum of $10-20 \%$ tree crown cover (including natural and plantation forests), as well as of the FAO concept of deforestation, that is, depletion of tree crown cover (compared with the crop-specific concept of growing stock depletion used here).
Thus, from the divergent definitions, the data produced could only be taken as a rough indication and need to be crosschecked against reported evidence of deforestation (or otherwise verified). The number of countries included was 66, as only cases of developing nations with FAO-reported deforestation were included.

ASSESSING ENVIRONMENTAL CRITICALITY

To assess tobacco's environmental impact on a national scale, criticality measures of forest resource availability were used. Assuming a need of one cubic metre of fuelwood for purposes such as cooking per inhabitant per year and an annual growth of $4 \mathrm{~m}^{3}$ of usable (solid) woody biomass in the form of stem, branches, and twigs, which is a rather high estimate for dry forests and woodlands (especially when compared with $0.5 \mathrm{~m}^{3}$ of solid wood used here ${ }^{20}$ ), a forested area of 0.25 ha per capita would be needed to cover the fuelwood demand on a sustained yield basis. ${ }^{17}$

\section{Results}

TANZANIA

In the low-income, African nation of Tanzania (tables 2 and 3), average annual tobacco production between 1991 and 1995 was 21645 tonnes. The use of wood in the form of firewood and polewood was prevalent for all tobacco varieties grown, that is, flue-cured (81.5\% of total production), (dark) fire-cured $(18.2 \%)$, and (air-cured) burley tobacco $(0.3 \%)$. Experiments with coal in the artificial curing of flue have failed, and no cost-effective alternatives to wood have so far been introduced on a large scale. Thus, $100 \%$ of flue-cured tobacco produced uses wood. From the annual rates of wood usage per crop variety grown $\left(\right.$ in $\mathrm{stm}^{3} / \mathrm{t}$ ) -flue-cured $=33.1$ (fuel $=$ 33.0, poles $=0.1$ ), fire-cured $=37.5$ (fuel $=37$, poles $=0.5)$, and burley $=5.0$ (only polewood $)$, the total stacked farmwood consumed by tobacco amounts to $731634 \mathrm{~m}^{3}$ or the equivalent of $314603 \mathrm{t}$, that is: ( $(17640 \mathrm{t}$ of flue $\times$ $33.1)+(3930 \mathrm{t}$ of fire-cured $\times 37.5)+(75 \mathrm{t}$ of burley $\times 5.0)) \times 0.43$.

Since only $7 \%$ of the flue farmers are known to use their own woodfuel plantings, presumably $93 \%$ of the wood requirements for all tobaccos (292 580 t) is taken from open, accessible natural forests and woodlands. If managed in a sustainable manner, with no more than the MAI taken, this translates into 585160 ha of natural woody biomass area (dry forests, woodlands) needed, that is, 292580 divided by 0.5 , or the equivalent of 19505 ha of (hypothetical) plantation forest area, that is, 292580 divided by 15 . Under the assumption that the woody biomass required is totally removed by depleting GS, the amount of forests and woodlands deforested is 10836 ha, or 292580 divided by 27 . Compared with the total deforestation of 323000 ha each year during the period considered, tobacco's share amounts to $3.4 \%$. Deforestation caused by tobacco farming is considered to be "high" but not "serious" on a national scale. This assessment is largely con- 
firmed by indicators of environmental criticality such as the share of forest in total land $(36.8 \%)$ which is far above the forest cover required to ensure adequate fuelwood supplies $(8.4 \%)$, that is, $33.6 \times 0.25$. Although the share of land under tobacco in 1992 to 1997 $(1.1 \%)$ was above the global mean $(0.7 \%)$, expansion of tobacco land was far below that of arable land.
In the perception of Tanzania's national tobacco services: "The country has plenty of uncultivated land suitable for tobacco production ... [and] a large potential to increase production of flue and fire cured tobacco through acreage expansion," 22 thus confirming the national trend assessed. The impact of tobacco-related deforestation will presumably be felt more on a regional, provincial, or

Table 2 Usage of wood in tobacco production and its impact upon forest resources in the developing world ${ }^{\star}, 1990-1995$

\begin{tabular}{|c|c|c|c|c|c|c|c|c|c|c|c|c|c|c|c|c|c|c|c|c|c|c|}
\hline \multirow{2}{*}{$\begin{array}{l}\text { Developing } \\
\text { countries }\end{array}$} & \multicolumn{4}{|c|}{ Flue-cured tobacco } & \multicolumn{2}{|c|}{$\begin{array}{l}\text { Fire-cured } \\
\text { tobacco }\end{array}$} & \multicolumn{2}{|l|}{ Bur } & \multicolumn{2}{|l|}{ Das } & \multicolumn{2}{|l|}{ Ori } & \multicolumn{2}{|l|}{$D a c$} & \multicolumn{2}{|l|}{$L a c$} & \multicolumn{3}{|c|}{$\begin{array}{l}\text { Wood } \\
\text { consumption }\end{array}$} & \multicolumn{3}{|c|}{ Deforestation } \\
\hline & (a) & (b) & (c) & (d) & (b) & (d) & (b) & (e) & (b) & (e) & (b) & (e) & (b) & (e) & (b) & (e) & $(f)$ & (g) & (h) & (i) & (j) & (k) \\
\hline \multicolumn{23}{|c|}{ Serious impact ${ }^{\star \star}$} \\
\hline South Korea & 85.5 & 62.1 & 50 & 19.1 & 0.0 & 0.0 & 37.9 & 3.8 & 0.0 & 0.0 & 0.0 & 0.0 & 0.0 & 0.0 & 0.0 & 0.0 & 272.2 & 58 & 157.9 & 5846 & 13.0 & 45.0 \\
\hline Uruguay & 1.4 & 89.3 & 90 & 15.1 & 0.0 & 0.0 & 3.6 & 3.8 & 7.1 & 3.8 & 0.0 & 0.0 & 0.0 & 0.0 & 0.0 & 0.0 & 7.6 & 58 & 4.4 & 162 & 0.4 & 40.6 \\
\hline Bangladesh & 55.0 & 33.4 & 36 & 17.1 & 0.0 & 0.0 & 2.4 & 5.0 & 61.6 & 5.0 & 0.0 & 0.0 & 0.2 & 5.0 & 2.4 & 5.0 & 128.0 & 58 & 74.2 & 2750 & 9.0 & 30.6 \\
\hline Malawi & 125.4 & 19.0 & 100 & $18.0 \dagger$ & 8.3 & 23.5 & 71.6 & 5.0 & 0.7 & 5.0 & 0.4 & 5.0 & 0.0 & 0.0 & 0.0 & 0.0 & 485.4 & 80 & 388.3 & 14382 & 55.0 & 26.1 \\
\hline Jordan & 2.8 & 100.0 & 50 & 19.1 & 0.0 & 0.0 & 0.0 & 0.0 & 0.0 & 0.0 & 0.0 & 0.0 & 0.0 & 0.0 & 0.0 & 0.0 & 11.7 & 58 & 6.8 & 252 & 1.0 & 25.2 \\
\hline Pakistan & 96.0 & 48.1 & 100 & 19.1 & 0.0 & 0.0 & 1.0 & 5.0 & 21.6 & 5.0 & 18.0 & 5.0 & 0.0 & 0.0 & 11.3 & 5.0 & 486.1 & 58 & 282.0 & 10443 & 55.0 & 19.0 \\
\hline Syria & 18.5 & 26.1 & 50 & 19.1 & 0.0 & 0.0 & 21.0 & 3.8 & 0.0 & 0.0 & 50.5 & 3.8 & 0.0 & 0.0 & 2.5 & 3.8 & 42.3 & 58 & 24.5 & 909 & 5.0 & 18.2 \\
\hline China & 3049.0 & 89.0 & 0 & NA $†$ & 0.0 & 0.0 & 2.3 & 5.0 & 7.9 & 5.0 & 0.3 & 5.0 & 0.6 & 5.0 & 0.0 & 0.0 & 722.8 & 58 & 419.2 & 15527 & 87.0 & 17.8 \\
\hline Zimbabwe & 202.3 & 94.7 & 30 & $28.0 \dagger$ & 0.0 & 0.0 & 5.3 & 5.0 & 0.0 & 0.0 & $<0.1$ & 5.0 & 0.0 & 0.0 & 0.0 & 0.0 & 715.0 & 30 & 214.5 & 7945 & 50.0 & 15.9 \\
\hline Mean $(n=9)$ & 404.0 & 62.4 & 56 & 17.2 & $(0.9)$ & $(2.6)$ & 16.1 & 4.0 & 11.0 & 2.6 & 7.7 & 2.6 & $<0.1$ & 1.1 & 1.8 & 1.5 & 319.0 & 57 & 174.6 & 6468 & 30.6 & 26.5 \\
\hline \multicolumn{23}{|l|}{ High impact ${ }^{\star *}$} \\
\hline Argentina & 95.3 & 55.2 & 67 & 12.1 & $<0.1$ & 23.5 & 35.6 & 3.8 & 8.4 & 3.8 & 0.0 & 0.0 & 0.0 & 0.0 & 0.7 & 3.8 & 254.1 & 90 & 228.7 & 8470 & 89.0 & 9.5 \\
\hline Tunisia & 6.3 & 0.0 & 0.0 & 0.0 & 0.0 & 0.0 & 100.0 & 3.8 & 0.0 & 0.0 & 0.0 & 0.0 & 0.0 & 0.0 & 0.0 & 0.0 & 10.4 & 58 & 6.0 & 223 & 3.0 & 7.4 \\
\hline Burundi & 1.4 & 0.0 & 0.0 & 0.0 & 0.0 & 0.0 & 0.0 & 0.0 & 100.0 & 5.0 & 0.0 & 0.0 & 0.0 & 0.0 & 0.0 & 0.0 & 3.1 & 58 & 1.8 & 66 & 1.0 & 6.6 \\
\hline Haiti & 0.7 & 15.5 & 90 & 15.1 & 0.0 & 0.0 & 55.9 & 5.0 & 28.7 & 5.0 & 0.0 & 0.0 & 0.0 & 0.0 & 0.0 & 0.0 & 1.9 & 58 & 1.1 & 41 & 1.0 & 4.1 \\
\hline Cuba & 27.3 & 0.0 & 0.0 & 0.0 & 0.0 & 0.0 & 0.0 & 0.0 & 0.0 & 0.0 & 0.0 & 0.0 & 100.0 & 3.8 & 0.0 & 0.0 & 44.6 & 58 & 25.8 & 957 & 24.0 & 4.0 \\
\hline Dominican & & & & & & & & & & & & & & & & & & & & & & \\
\hline Republic & 20.4 & 14.9 & 90 & 15.1 & 0.0 & 0.0 & 10.2 & 3.8 & 74.9 & 3.8 & 0.0 & 0.0 & 0.0 & 0.0 & 0.0 & 0.0 & 46.1 & 58 & 26.7 & 99 & 26.0 & 3.8 \\
\hline Philippines & 84.0 & 54.1 & 100 & 19.1 & 0.0 & 0.0 & 29.7 & 3.8 & 0.0 & 0.0 & $<0.1$ & 3.8 & 16.2 & 3.8 & 0.0 & 0.0 & 436.0 & 58 & 252.9 & 9367 & 262.0 & 3.6 \\
\hline Tanzania & 21.6 & 81.5 & 100 & 33.1 & 18.2 & 37.5 & 0.3 & 5.0 & 0.0 & 0.0 & 0.0 & 0.0 & 0.0 & 0.0 & 0.0 & 0.0 & 314.6 & 93 & 292.6 & 10836 & 323.0 & 3.4 \\
\hline Chile & 15.7 & 28.9 & 90 & 15.1 & 0.0 & 0.0 & 67.5 & 3.8 & 2.6 & 1.0 & 1.0 & 3.8 & 0.0 & 0.0 & 0.0 & 0.0 & 44.4 & 58 & 25.8 & 955 & 29.0 & 3.3 \\
\hline El Salvador & 1.0 & 64.5 & 90 & 15.1 & 0.0 & 0.0 & 35.5 & 3.8 & 0.0 & 0.0 & 0. & 0.0 & 0.0 & 0. & 0.0 & 0.0 & 4.5 & 58 & 2.6 & 97 & 4.0 & 2.4 \\
\hline Iran & 25.0 & 21.2 & 50 & 19.1 & 0.0 & 0.0 & 0.0 & 0.0 & 28.8 & 1.0 & 50.0 & 1.0 & 0.0 & 0.0 & 0.0 & 0.0 & 30.3 & 58 & 17.6 & 652 & 28.0 & 2.3 \\
\hline Morocco & 4.8 & 5.7 & 100 & 28.1 & 0.0 & 0.0 & 90.6 & 3.8 & 3.7 & 3.8 & 0.0 & 0.0 & 0.0 & 0.0 & 0.0 & 0.0 & 10.6 & 58 & 6.2 & 228 & 12.0 & 1.9 \\
\hline Mean $(n=12)$ & 25.3 & 28.5 & 65 & 14.3 & (1.5) & $(5.1)$ & 35.4 & 3.1 & 20.6 & 2.0 & 4.3 & 0.7 & 9.7 & 0.6 & $<0.1$ & 0.3 & 100.1 & 64 & 74.0 & 2740 & 66.8 & 4.4 \\
\hline Medium $i$ & & & & & & & & & & & & & & & & & & & & & & \\
\hline Thailand & 79.1 & 44.7 & 50 & 19.1 & 0.0 & 0.0 & 35.5 & 3.8 & 0.0 & 0.0 & 14.6 & 3.8 & 5.2 & 3.8 & 0.0 & 0.0 & 217.6 & 58 & 126.2 & 4674 & 329.0 & 1.4 \\
\hline Vietnam & 30.3 & 35.0 & 50 & 19.1 & 0.0 & 0.0 & 0.0 & 0.0 & 65.0 & 5.0 & 0.0 & 0.0 & 0.0 & 0.0 & 0.0 & 0.0 & 86.0 & 58 & 49.9 & 1847 & 135.0 & 1.4 \\
\hline Togo & 2.0 & 0.0 & 0.0 & 0.0 & 50.0 & 23.5 & 0.0 & 0.0 & 50.0 & 5.0 & 0.0 & 0.0 & 0.0 & 0.0 & 0.0 & 0.0 & 12.3 & 58 & 7.1 & 263 & 19.0 & 1.4 \\
\hline Nigeria & 9.2 & 19.0 & 100 & 62.1 & 0.0 & 0.0 & 0.0 & 0.0 & 11.6 & 5.0 & 0.0 & 0.0 & 0.0 & 0.0 & 69.4 & 5.0 & 62.8 & 70 & 44.0 & 1629 & 121.0 & 1.3 \\
\hline Jamaica & 2.3 & 51.8 & 90 & 15.1 & 0.0 & 0.0 & 0.0 & 0.0 & 0.0 & 0.0 & 0.0 & 0.0 & 48.2 & 3.8 & 0.0 & 0.0 & 8.9 & 58 & 5.2 & 192 & 16.0 & 1.2 \\
\hline Sri Lanka & 9.0 & 54.5 & 36 & 19.1 & 0.0 & 0.0 & 15.0 & 5.0 & 18.4 & 5.0 & 0.0 & 0.0 & 0.0 & 0.0 & 12.1 & 5.0 & 23.4 & 25 & 5. & 21 & 20.0 & 1.1 \\
\hline Honduras & 7.7 & 24.0 & 100 & 18.1 & 0.0 & 0.0 & 57.1 & 5.0 & 0.0 & 0.0 & 0.4 & 5.0 & 16.7 & 5.0 & 1.8 & 5.0 & 27.1 & 90 & 24.4 & 90 & 102.0 & 0.9 \\
\hline Ethiopia & 3.5 & 50.0 & 100 & 28.1 & 0.0 & 0.0 & 0.0 & 0.0 & 0.0 & 0.0 & 50.0 & 5.0 & 0.0 & 0.0 & 0.0 & 0.0 & 24.9 & 58 & 14.4 & 535 & 62.0 & 0.9 \\
\hline Lebanon & 5.0 & 0.0 & 0.0 & 0.0 & 0.0 & 0.0 & 0.0 & 0.0 & 0.0 & 0.0 & 100.0 & 1.0 & 0.0 & 0.0 & 0.0 & 0.0 & 2.2 & 58 & 1.2 & 46 & 5.0 & 0.9 \\
\hline Uganda & 5.8 & 72.0 & 100 & 28.1 & 15.8 & 23.5 & 5.3 & 5.0 & 0.0 & 0.0 & 0.0 & 0.0 & 6.9 & 5.0 & 0.0 & 0.0 & 61.2 & 20 & 12.2 & 453 & 59.0 & 0.8 \\
\hline Zambia & 5.7 & 83.2 & 100 & 28.1 & 0.0 & 0.0 & 16.8 & 5.0 & 0.0 & 0.0 & 0.0 & 0.0 & 0. & 0.0 & 0.0 & 0.0 & 59.6 & 90 & 53.6 & 1986 & 264.0 & 0.8 \\
\hline Guatemala & 13.4 & 8.0 & 90 & 15.1 & 0.0 & 0.0 & 91.4 & 3.8 & 0.0 & 0.0 & 0.1 & 3.8 & 0.0 & 0.0 & 0.5 & 3.8 & 26.5 & 58 & 15.4 & 569 & 82.0 & 0.7 \\
\hline Trinidad and & & & & & & & & & & & & & & & & & & & & & & \\
\hline Tobago & 0.2 & 100.0 & 90 & 15.1 & 0.0 & 0.0 & 0.0 & 0.0 & 0.0 & 0.0 & 0.0 & 0.0 & 0.0 & 0.0 & 0.0 & 0.0 & 1.0 & 58 & 0.6 & 21 & 3.0 & 0.7 \\
\hline Colombia & 38.0 & 11.0 & 90 & 15.1 & 0.0 & 0.0 & 11.8 & 3.8 & 73.3 & 3.8 & 0.0 & 0.0 & 0.7 & 3.8 & 3.3 & 3.8 & 79.6 & 58 & 46.2 & 1710 & 262.0 & 0.7 \\
\hline Mean $(n=14)$ & 15.1 & 39.5 & 71 & 20.2 & $(4.7)$ & (3.4) & 16.6 & 2.2 & 15.6 & 1.7 & 11.8 & 1.3 & 5.6 & 1.5 & 6.2 & 1.6 & 49.5 & 58 & 29.0 & 1075 & 105.6 & 1.0 叫 \\
\hline Low impact ${ }^{\star *}$ & & & & & & & & & & & & & & & & & & & & & & \\
\hline Mean $(n=14) \ddagger$ & 55.7 & 45.0 & 84 & 18.0 & 3.4 & 7.1 & 15.2 & 3.0 & 28.1 & 3.0 & $<0.1$ & 0.3 & 1.7 & 1.1 & 6.7 & 1.2 & 226.8 & 56 & 61.1 & 2263 & 450.0 & $0.4 \pi$ \\
\hline Minor impact ${ }^{\star *}$ & & & & & & & & & & & & & & & & & & & & & & \\
\hline Mean $(\mathrm{n}=17) \rrbracket$ & 2.6 & 18.5 & 39 & 8.0 & 9.8 & 4.0 & 11.9 & 1.2 & 36.5 & 2.6 & $<0.1$ & 0.2 & 18.5 & 1.6 & 4.8 & 1.3 & 6.4 & 58 & 3.7 & 137 & 136.7 & 0.19 \\
\hline Minor-to-serious & mpact & & & & & & & & & & & & & & & & & & & & & \\
\hline Mean $(n=66)$ & 75.4 & 36.4 & 62 & 15.1 & 4.6 & 4.1 & 18.5 & 2.5 & 23.9 & 2.4 & 4.3 & 0.9 & 8.1 & 1.2 & 4.3 & 1.2 & 121.9 & 59 & 57.3 & 2124 & 169.4 & $4.6 \pi$ \\
\hline
\end{tabular}

Bur = burley tobacco; Das $=$ dark air/sun-cured tobaccos; Ori $=$ oriental tobacco $;$ Dac $=$ dark air-cured (cigar) tobacco Lac $=$ light air-cured tobaccos; $\mathrm{NA}=$ not applicable.

$\star$ Developing world as defined by FAO. ${ }^{16}$

†No polewood usage assumed, as mostly brick-built barns.

¥Including 14 countries: Ivory Coast, Ghana, Sierra Leone, Angola, Mozambique, Madagascar, Laos, Myanmar/Burma, Indonesia, Malaysia, Costa Rica, Mexico, Brazil, Venezuela.

§Including 17 countries: Chad, Mali, Benin, Liberia, Cameroon, Central African Republic, Congo, Algeria, Cambodia, Solomon Islands, Nicaragua, Panama,

Bolivia, Ecuador, Guyana, Paraguay, Peru.

$\uparrow$ Arithmetical mean of single values.

${ }^{\star \star}$ For an explanation of the classification of tobacco-related deforestation, see text.

(a) Mean annual tobacco production ('000 tonnes), 5-year average of 1991-95. ${ }^{19}$

(b) Percentage in total production ${ }^{19}$

(c) Percentage of flue-produce using fuelwood. ${ }^{10}$

(d) Rate of combined fuel/polewood usage (stacked cubic metres per tonne per year). ${ }^{10}$

(e) Rate of polewood usage (stacked cubic metres per tonne per year). ${ }^{10}$

(f) Total annual consumption of solid wood ('000 tonnes).

(g) Percentage of wood taken as free goods from open, accessible (common) land ${ }^{10}$

(h) Solid wood in (g) ('000 tonnes).

(i) Area of natural woody biomass removed (ha).

(j) Total annual deforestation ('000 ha). ${ }^{16}$

(k) Percentage of tobacco-related deforestation. 
Table 3 Environmental criticality caused by tobacco's impact upon forest resources

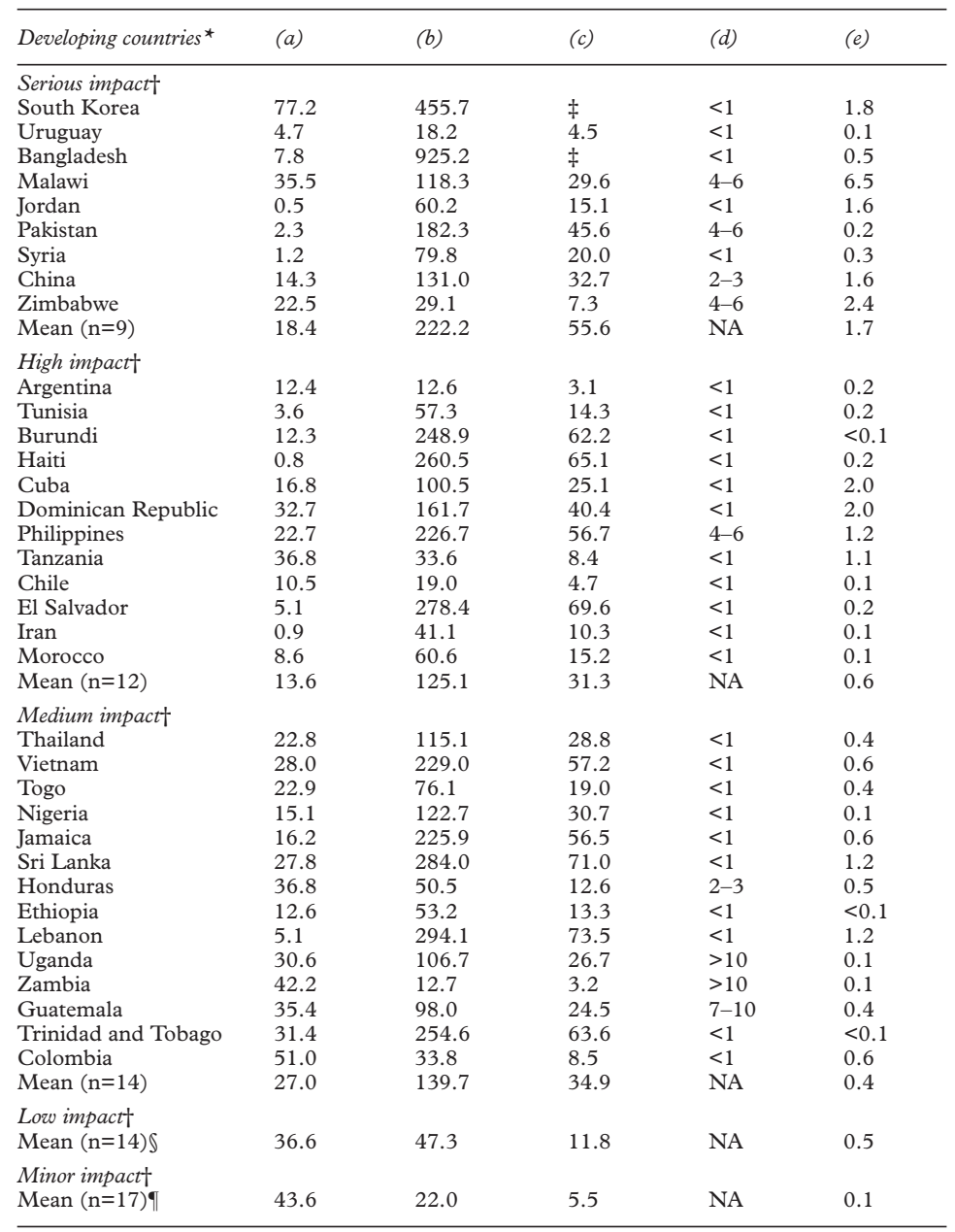

NA $=$ not applicable

${ }^{\star}$ Growing countries of the developing world as defined by FAO. ${ }^{16}$

†For an explanation of the classification of tobacco-related deforestation, see text.

$\neq$ Value exceeds total of $100 \%$.

§Including 14 countries: Ivory Coast, Ghana, Sierra Leone, Angola, Mozambique, Madagascar, Laos, Myanmar/Burma, Indonesia, Malaysia, Costa Rica, Mexico, Brazil, Venezuela.

IIncluding 17 countries: Chad, Mali, Benin, Liberia, Cameroon, Central African Republic,

Congo, Algeria, Cambodia, Solomon Islands, Nicaragua, Panama, Bolivia, Ecuador, Guyana,

Paraguay, Peru.

(a) Total forest as percentage of land area in 1995.

(b) Population density in 1995 (inhabitants per square kilometre).

(c) Percentage of forest cover required in 1995 to supply population with one cubic metre of fuelwood per inhabitant.

(d) Ratio of tobacco to arable land growth 1982-1997.

(e) Percentage of tobacco in arable land 1992/1997.

district level. Taking, for example, the area of Tabora/Urambo, the largest flue-producing region of the country, the area had early been identified as a region at risk, if mitigation of the losses of natural forest cover due to tobacco were not undertaken. ${ }^{23}{ }^{24}$ In the early 1990s, it was reported that farmers had to travel as far as $10 \mathrm{~km}$ to get wood, and that effects of tobaccorelated desertification were already visible in terms of forest removal, droughts, irregular rains, and whirlwinds, which had been uncommon in the area before. ${ }^{25}$ Although nearly 11000 ha of tobacco-related annual deforestation were estimated to occur on a national scale, the following estimates rank higher.

- At the end of 1980, the steady increases of tobacco production since independence had been predicted to cause "overexploitation" of woodlands as high as $42000 \mathrm{ha}^{26}$ (the value clearly relates to forest degradation, that is, using more than MAI, but not depleting GS).

- For the agricultural season 1989 to 1990, the annual loss of forest cover due to tobacco curing (not including usages of polewood) was estimated to be 13000 ha by using a laboratory design of one curing process to arrive at a national estimate. ${ }^{27}$

Curing of tobacco was considered by Siddiqui and $\mathrm{Rajabu}^{27}$ to be the second largest consumer of wood after the domestic sector, producing 4356 million cubic metres of carbon dioxide and 238 million cubic metres of carbon monoxide per season. Taken together, the "deforestation rate and level of discharge of polluting gases to the atmosphere" was regarded as "a threat to the integrity of the environment" (figure 2).

THE GLOBAL VIEW

Considering the annual amount of wood required for tobacco farming in 1990-1995 on a global scale (11.4 million tonnes), half - mostly for the purpose of curing Virginia (flue-cured tobacco)-is presumably not provided from own and legitimate sources (5.7 million tonnes), but taken from open, accessible (common) land and native forests (table 1). Given the assumption that the natural woody biomass area is managed in a sustained-yield manner, that is, no overcutting/ overexploitation occurs, tobacco farming requires 11.4 million ha of those types of natural vegetation where tobacco is commonly grown (medium types of biomass potentials such as woodlands, forest/woodland regrowths and highland cultivation mosaics). To substitute the impact on native forests and woodlands, the equivalent (hypothetical) area under plantation trees is 503000 ha.

Assuming, however, that deficit wood is not harvested from natural vegetation in a sustainable manner, but the growing stock depleted instead, the amount of natural woody biomass consumed and removed annually by tobacco is estimated to be 211000 ha. As 93\% of tobacco-related deforestation occurs in growing countries of the developing world, and as the decrease of 14600 ha in the developed world (Romania, Japan, South Africa) is assumed to be completely offset by wood brought in from sources other than deforesting common lands, the amount of forest cover lost annually due to tobacco growing (in the developing world) is $196400 \mathrm{ha}$ ).

Considering total deforestation, the cumulative global net losses of all forested areas in the five-year period 1990-1995 were 56.3 million ha, ${ }^{16}$ and the global net loss of forest was 11.3 million ha. Thus, tobacco-related deforestation amounts to $1.7 \%$ of the net amount of forest cover removed annually on a global scale. In terms of the rate of total annual deforestation $(0.65 \%$ worldwide $)$, it was highest in the tropical zone of the developing world, especially in tropical Asia/Oceania $(0.98 \%) .{ }^{16}$ Reflecting these trends, tobacco's share in forest removal is highest in developing 


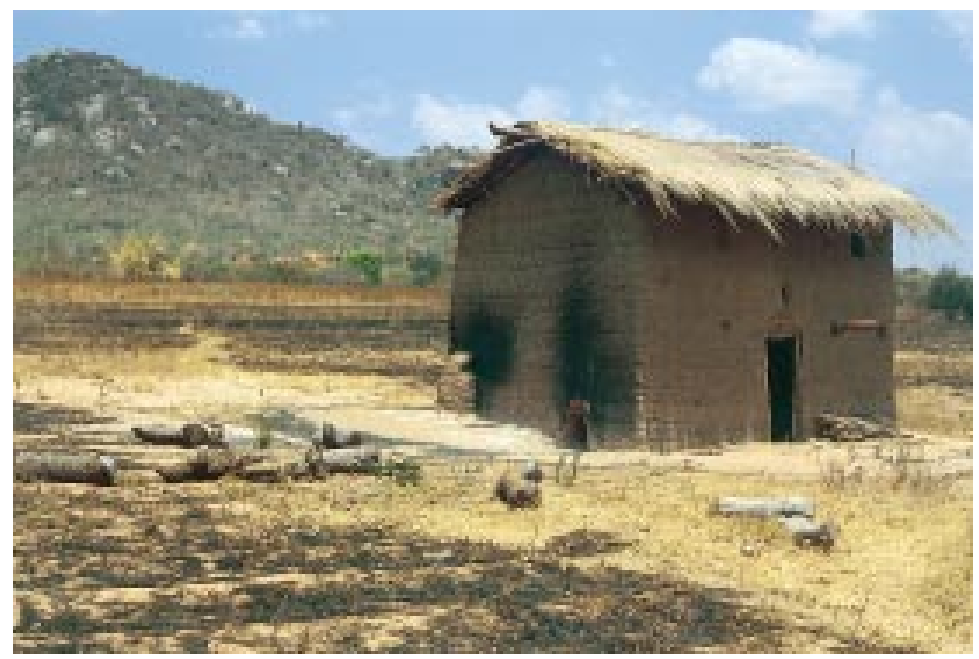

Figure 2 Remaining pieces of firewood surrounding a curing barn in southern Tanzania. An estimated tractor-load of wood (approximately 3 tonnes of solid wood) taken from common woodlands was used to cure the total harvest of tobacco grown on fields around the barn in the 1997/98 season. The hills in the background have been denuded for about 35 years, because of overcutting for tobacco curing.

countries of Asia/Oceania (3.7\%) and lowest in the Americas $(0.6 \%)$.

CRITICALITY IN THE DEVELOPING WORLD

On the basis of 66 growing countries of the developing world which were found to have both tobacco-induced losses of forest cover and FAO-reported ${ }^{16}$ incidences of deforestation (table 2), tobacco's share in total annual deforestation occurring in 1990-1995 is estimated to be $4.6 \%$ as a mean national average $($ median $=0.7 \%, \operatorname{mode}=<0.1 \%)$. No FAO-reported deforestation, but an estimated tobacco-related demand of area under trees, exists in another 13 developing countries among which are major consumers of wooded areas for tobacco such as India (an estimated 44200 ha), Turkey (9000 ha), North Korea (2100 ha), Yemen (500 ha) and Mauritius (200 ha), while the other remaining countries have losses of approximately 50 ha or less annually. Like any other developing countries with missing tobacco production figures, however having reported losses of forest cover, these cases are not considered here. Under the assumption of self-sufficiency in wood for tobacco, no crop-specific deforestation is found in Kenya and Congo/Zaire, whereas the annual overall deforestation there amounts to 3000 ha and 740000 ha, respectively.

To assess tobacco's impact upon deforestation, a ranking of developing countries according to tobacco's share in total deforestation is based on the global mean of net losses of forest cover $(1.7 \%)$, the national mean $(4.6 \%)$ and the median $(0.7 \%)$, allowing the following classification of impact.

- "Serious"-higher than national mean plus standard deviation (>13.9\%)

- "High"-higher than global mean (1.7$13.9 \%)$

- "Medium"-higher than median, but lower than global mean (0.7-1.7\%)

- "Low"-lower than median, but higher than half of it $(0.3-0.7 \%)$
- "Minor"-lower than half the median $(<0 . \%)$

Out of a total of 66 developing countries thus classified, more than half (35) prove to have a "medium" (on average $1.0 \%$ of total deforestation), "high" (4.4\%), or "serious" (26.5\%) degree of tobacco-related deforestation. The countries with a medium-to-serious impact, among which are leading producers such as China, Zimbabwe, and Malawi, hold more than half the global tobacco production and account for around $60 \%$ of estimated forest cover losses in the developing world (altogether $111143 \mathrm{ha}$ ). If ranked by the absolute amount of forests and woodlands removed, more than 10000 ha were annually removed in China, Malawi, Tanzania, and Pakistan. The average amount of natural vegetation removed per developing country is more than 2000 ha or about $5 \%$ of total national deforestation, while it rises, on average, to around a quarter of all deforestation in the group of seriously affected producers. As a major factor contributing to crop-specific deforestation, the global mean of flue-cured produce using wood is only about $12 \%$, but increases to a mean $62 \%$ in the producer countries with minor-to-serious tobacco-related deforestation.

Holding tobacco's share in total deforestation against indicators of environmental criticality such as forest resource availability and population development (table 3), the groups of developing countries having a medium-to-serious degree of tobacco-related deforestation on average do not dispose of a forested land cover sufficient to provide for the fuelwood needs of their respective populations. Although the present forest cover turns out to be sufficient in developing countries with lowto-minor tobacco-induced deforestation, the deficit is highest in the group of countries having a serious and high degree of tobacco-induced deforestation (although not in Zimbabwe, Tanzania, and Chile, while emerging criticality exists in Uruguay and Malawi). Taking indicators such as arable versus tobacco land development, it could further be concluded that-besides population-bound forest resource availability - tobacco's share in total arable land is likely to constitute another factor explaining data variation in relative deforestation. For example, in the group of countries with serious tobacco-related deforestation, more countries could be found where the growth of land under tobacco has exceeded the expansion of arable land and where large or excessive tracts of tobacco in all arable land exist.

AMERICAS

In the Americas, the present share of global tobacco grown is about $22 \%$. The annual losses of vegetational cover in 1990-1995 were offset by forest increases in the developed nations (Canada, United States), resulting in net losses of around 5.8 million ha, and the total amount of natural vegetation removed by tobacco in Latin America is estimated to be around 37200 ha annually. Thus, among the continents, America holds the lowest share of 


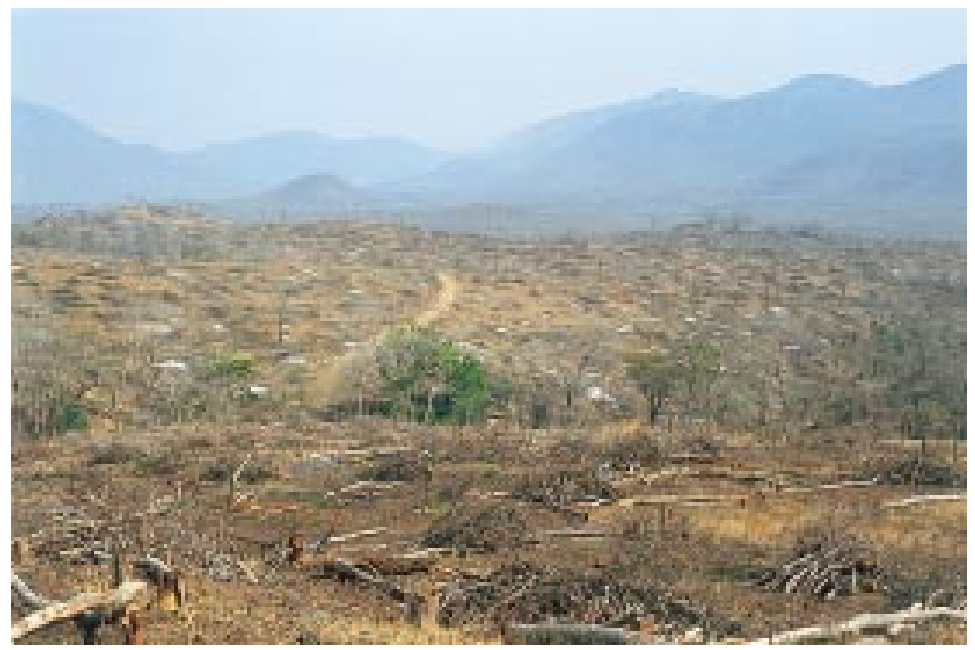

Figure 3 Several hundred hectares of natural ("miombo") woodlands were cleared in a wood-energy project financed by the World Bank, to provide wood to nearby tobacco farms and urban users in southern Malawi. Unfavourable prices at the time resulted in the burning of large areas of tree cover. The area is an environmentally critical watershed zone of the east African Rift Valley, and is now a government-owned plantation forested with fast-growing exotic species, such as eucalyptus.

tobacco-related forest removal $(0.6 \%)$. A medium-to-serious degree of deforestation by tobacco presumably exists in parts of South America (Argentina, Uruguay, Chile, Colombia), the Caribbean (Cuba, Dominican Republic, Haiti, Jamaica, Trinidad and Tobago) and central America (Honduras, El Salvador, Guatemala). The situation seems especially critical in Cuba and the Dominican Republic, with both holding large shares of tobacco in arable land and not having sufficient forest cover. Although having small amounts of land under tobacco, environmental criticality could be assumed in Haiti, El Salvador, Jamaica, and Trinidad and Tobago. Despite a sufficient forest cover, looming wood scarcity due to tobacco is likely to emerge in Honduras and Guatemala where tobacco land expansion has exceeded the growth of arable land during the past 15 years. Among other developing countries with low-to-minor degrees of tobacco-related deforestation, only Costa Rica, Ecuador, and Paraguy show a trend towards emerging criticality (while no such indication is found in Brazil).

AFRICA

The share of African tobacco in world production has tripled from $2 \%$ in the 1930 s to $6 \%$ in the 1990 s. At present, nearly $90 \%$ of continental production originates from producer countries of the miombo zone, an ecosystem of the southeastern highlands bearing dry forests and woodlands. ${ }^{28}$ None of the annual losses of vegetational cover (3.0 million ha) was offset by forest increases. Forest removal by tobacco is estimated to be approximately 41900 ha annually. Thus, Africa holds a medium share of tobacco-related forest removal in deforestation $(1.4 \%)$. A medium-to-serious degree of tobacco-related deforestation exists in southern and eastern Africa (Malawi, Zimbabwe, Zambia, Tanzania, Uganda, Burundi, Ethiopia), in parts of north Africa (Morocco, Tunisia), and west Africa (Togo, Nigeria). The situation seems close to criticality, however, only in parts of the miombo-covered highlands in southeast Africa. In Malawi, for example, large shares of tobacco under arable land exist, with arable land having expanded at lower rates than tobacco, whereas forest cover still exists to a sufficient degree (not so in Burundi), but tending towards criticality (figure 3 ). General wood scarcity is already a major factor in subtropical north Africa (including Algeria with minor deforestation) as well as in most of tropical west Africa where indicators tend towards criticality more among SudanoSahelian producers such as Nigeria (including Chad and Mali with minor deforestation) than among Sudano-Guinean producers such as Togo (including Ghana, Ivory Coast, Sierra Leone, Benin, Liberia, and Cameroon with low-to-minor deforestation). No significant indication of tobacco-related forest removal, however, is found in producer countries of the rainforest zone such as Congo and the Central African Republic.

ASIA/OCEANIA

In Asia and Oceania, the share of tobacco in global production has been on a constant rise from approximately $30 \%$ in the 1950 s to approximately $63 \%$ at present. The annual losses of vegetational cover were assumed to be partly offset by forest increases in developed countries (Australia and New Zealand, not so in Japan), resulting in net losses of around 3.1 million hectares, and the amount of natural vegetation removed by tobacco is estimated to be around 117300 ha annually. Thus, among the continents, Asia/Oceania holds the largest share of tobacco-related forest removal (3.7\%). An estimated medium-to-serious degree of deforestation due to tobacco exists in subtropical climates-east Asia (China, South Korea) and the middle/near east region (Jordan, Syria, Iran, Lebanon), as well as in tropical climatessouth Asia (Pakistan, Bangladesh, Sri Lanka) and continental as well as insular southeast Asia (Philippines, Thailand, Vietnam). Developing Asian countries hold the largest single share among tobacco producers with serious crop-specific deforestation. The situation seems especially critical in China, Pakistan, and the Philippines, where either large shares of tobacco are under arable land (China, Philippines) or recent, strong tobacco expansion has been experienced (China, Philippines, Pakistan) and forest cover is lower than required. The extent to which growing areas in the dry zone of the middle/near east region are affected is mainly seen as a general result of their limited arable land and vegetational cover. Criticality due to tobacco presumably exists in Sri Lanka, South Korea, Thailand, and Vietnam, whereas possible pressures emerging from the wood use of tobacco are not yet felt in Cambodia, Laos, Myanmar (Burma), Malaysia, and Indonesia (with low-to-minor crop-specific deforestation and still with large, forested areas). India was not included because no (net) overall deforestation due to the dynamic growth of commercial plantations has been reported, ${ }^{16}$ though tobacco's 
hypothetical consumption of wooded areas (44 $000 \mathrm{ha}$ ) by far exceeds annual forest increases (7000 ha).

\section{Discussion}

From the data presented, and in strategic terms of tobacco control, the hypothesis promoted by the tobacco industry that no significant negative effects, such as deforestation, are attributable to curing tobacco ${ }^{67}$ has to be challenged. The hypothesis turns out to be based on a (claimed) change in the economics of fuel choice, made in the absence of sufficient data to support such a claim, for a significant proportion of the developing world. In addition, the assertion is neither built upon deforestation data nor upon any other quantified ecological consequences. In the view of estimation values produced here, the hypothesis is refuted for the following reasons.

- Deforestation related to tobacco constitutes an issue of global relevance which could be found on all continents, on average contributing nearly $5 \%$ to overall deforestation in the respective growing countries of the developing world.

- The statement, made in the mid-1980s, that "most Asian tobacco-growing countries, and selected African countries have general fuelwood shortages and are therefore likely to experience deforestation", 8 should now be extended to encompass some southern American producers as well.

Although the global assessment of deforestation related to tobacco farming was estimated to be around 200000 ha annually in 1990-1995, compared with the higher value given for mid-1980, 1.2-2.5 million ha (although using the same design), ${ }^{23}$ the difference could be explained by a combination of the following two factors.

- Increased efforts of afforestation/ reforestation together with lower rates and higher efficiency of wood used in curing tobacco-for example, improvements in barn technology, growing use of agricultural wastes as fuel sources - could well have reduced tobacco's roundwood consumption and impact upon deforestation.

- The aggregated national data used here produce generally lower results than the global assessments based on single values previously undertaken-for example, 55 or $70 \mathrm{stm}^{3} / \mathrm{t}$ of global flue-cured tobacco using wood $^{2}$ - compared with a global mean of around $20 \mathrm{stm}^{3} / \mathrm{t}$ used here, ${ }^{10}$ different stacking factors (0.6 vs 0.43), different GS rates $\left(70 \mathrm{~m}^{3} / \mathrm{ha}\right.$ vs 27$)$ and different MAI rates $\left(2 \mathrm{~m}^{3} /\right.$ ha vs 0.5$)$.

Although the Nicotiana tabacum species is grown in more than 120 countries, thus constituting the most widely grown non-food crop (coffee is grown in 59 countries, jute and jutelike fibres in 25 , sisal in $15^{15}$ ) and although crop-specific deforestation occurs in developing countries spread all over the continents, tobacco has not been found to be part of the research agenda on global environmental change during the past 10 years.
On the basis of the estimated values produced, it is suggested that an empirical verification of the hypothetical deforestation outlined on a global scale should be undertaken. This should be done by surveying wood usage in randomly selected farms or growing areas in combination with remote sensing or geographical information systems (GIS) data. The current paradigmatic shift in research on global environmental change could be a useful platform for strategic involvement, especially involving the drive within the International Geosphere-Biosphere Programme (IGBP) examining natural as well as human dimensions of global change and modelling the total earth system using a more region-specific and problem-specific approach ("transects", "hot spots", "fragile environments", "regions at risk"). ${ }^{29-31}$

The basic principle of tobaco curing - using several units of (wood-based) energy to produce one unit of tobacco-has applied since the introduction of metal flues in the aftermath of the American Civil War and is not expected to change drastically in the foreseeable future. ${ }^{13}$ The recently claimed change in the choice of fuel economics should be reviewed, in that "most ingenious approaches towards reducing energy and cost requirements (in curing flue) ... are concerned only with modification of existing principles in the hope of maintaining the basic status quo a little longer." 13 Thus, in addition to public health oriented regulation of tobacco use, a major starting point in the field of environmentally oriented regulation could be to challenge the prevailing standards of transforming green leaves into a pre-industrial product that achieves a high nicotine content by consuming large amounts of natural resources.

The study has been funded partly by the World Bank project Tobacco control policies in developing countries (Washington, DC, United States) via a short-term consultancy and, to a larger degree, was made possible as part of the Research Priority Programme Social dimensions of global environmental change of the Deutsche Forschungsgemeinschaft (DFG, Bonn). The views represented are those of the author and not of the World Bank
or DFG.

1 Muller M. Tobacco and the third world - tomorrow's epidemic ? $A$ War on Want investigation into the production, promotion, and use of tobacco in the developing countries. London: War and use of tobacco

2 Goodland RJA, Watson C, Ledec G. Environmental management in tropical agriculture. Boulder: Westview Press, 1984. 3 World Bank. World Bank tobacco financing: The environmental/health case: background for policy formulation. Washington: Office of Environmental and Scientific Affairs, Projects Policy Department, 1984. (W0020/ 0087W/C2404.)

4 Bellagio statement on tobacco and sustainable development. Can Med Assoc F 1995;153:1109-10.

5 Food and Agriculture Organization of the United Nations. FAO brief on multisectoral collaboration on tobacco or health for the ECOSOC substantive session. Rome: FAO, 1998.

6 International Tobacco Growers' Association. Tobacco and the environment. East Grinstead, UK: ITGA, 1995.

7 International Tobacco Growers' Association. Deforestation and the use of wood for curing tobacco. East Grinstead, UK: ITGA, 1996

8 Fraser AI. The use of wood by the tobacco industry and the ecological implications. Edinburgh: International Forest Science Consultancy, 1986.

9 International Tobacco Growers' Association. The use of woodfuel for curing tobacco. A report by the International Tobacco Growers' Association. East Grinstead, UK: ITGA, 1997.

10 Geist $\mathrm{H}$. Transforming the fringe. Tobacco-related wood usage and its environmental implications. In: DelgadoCravidao F, Jussila H, Majoral R, eds. Consequences of globalization and deregulation on marginal and critical economic systems. Aldershot, UK: Ashgate, 1999. (In press.) 
11 Geist $\mathrm{H}$. Soil mining and societal responses. The case of tobacco in eastern miombo highlands. In: Lohnert B, tobacco in eastern miombo highlands. In: Lohnert B, Geist $\mathrm{H}$, eds. Coping with changing environments. Social
dimensions of endangered ecosystems in the developing world. Aldershot, UK: Ashgate, 1999. (In press.)

12 Andreae B. Farming, development and space - a world agricultural geography. Berlin: de Gruyter, 1981

13 Akehurst BC. Tobacco. London: Longman, 1981.

14 Goodman J. Tobacco in history. The cultures of dependence. London: Routledge, 1995.

15 Food and Agriculture Organization of the United Nations Production yearbook 1995;48:176-7, 1997;50:176-7.

16 Food and Agriculture Organization of the United Nations. State of the world's forests 1997. Rome: FAO, 1997.

17 Steinlin H. The decline of tropical forests. Q f Int Agric 1994;33:128-37.

18 Janzen DH. Tropical dry forests, The most endangered major tropical ecosystem. In: Wilson EO, ed. Biodiversity. major tropical ecosystem. In: Wilson EO, ed. Biodiversity.
Washington, DC: National Academy Press, 1988:130-7.

19 US Department of Agriculture, Foreign Agricultural Service. World tobacco situation. Washington, DC: USDA FAS, 1994; Circular Series FT-9407, 1997; Circular Series FT 9707.

20 Millington AC, Critchley RW, Douglas TD, et al. Estimating woody biomass in sub-saharan Africa. Washington, DC: World Bank, 1994

21 Booth A, Clarke J. Woodlands and forests. In: Chenje $M$ Johnson P, eds. State of the environment in Southern Africa, A report by the Southern African Research \& Documentation Centre in collaboration with IUCN-The World Conservation Union and the Southern African Development Community. Harare, Masero: SARDC, IUCN \& SADC, 1994:133-56.

22 Majengo OJ. Tobacco marketing review 1994/95. Dar es Salaam: Ministry of Agriculture, Marketing Development Bureau, 1996.
23 Boesen J, Mohele AT. The "success story" of peasant tobacco production in Tanzania. The political economy of a commodity producing peasantry. U.

24 Temu AB. Fuelwood scarcity and other problems associated with tobacco production in Tabora region, Tanzania. Morogoro: University of Dar es Salaam, Faculty of Agriculture, Forestry and Veterinary Science, 1979.

25 Waluye J. Environmental impact of tobacco growing in Tabora/Urambo, Tanzania. Tobacco Control 1994;3:252-4.

26 Misana SB. Agricultural development versus environmental conservation in Tanzania. The case of tobacco production. Afr Rev 1988;15:1-10.

27 Siddiqui KM, Rajabu H. Energy efficiency in current tobacco-curing practice in Tanzania and its consequences. Energy 1996;21:141-5.

28 Geist $\mathrm{H}$. How tobacco farming contributes to tropical deforestation. In: Abedian I, van der Merwe R, Wilkins N, et al, eds. Economics of tobacco control. Towards an optimal policy mix. Cape Town: Applied Fiscal Research Centre, University of Cape Town, 1998:232-44.

29 Global Change and Terrestrial Ecosystems. Global change impact on agriculture, forestry and soils. The work of GCTE Focus 3. Lyneham: GCTE Core Project Office, undated.

30 Turner BL II, Skole D, Sanderson S, et al. Land-use and land-cover change. Science/research plan. IGBP Report; 35. HDP Report; 7. Stockholm: International GeosphereBiosphere Programme, Human Dimensions of Global Environmental Change Programme, 1995.

31 Desanker P, Frost PGH, Justice CO, et al. The Miombo Network: Framework for a terrestrial transect study of land-use and land-cover change in the miombo ecosystems of Central Africa. Stockholm: International Geosphere-Biosphere Programme, 1997.

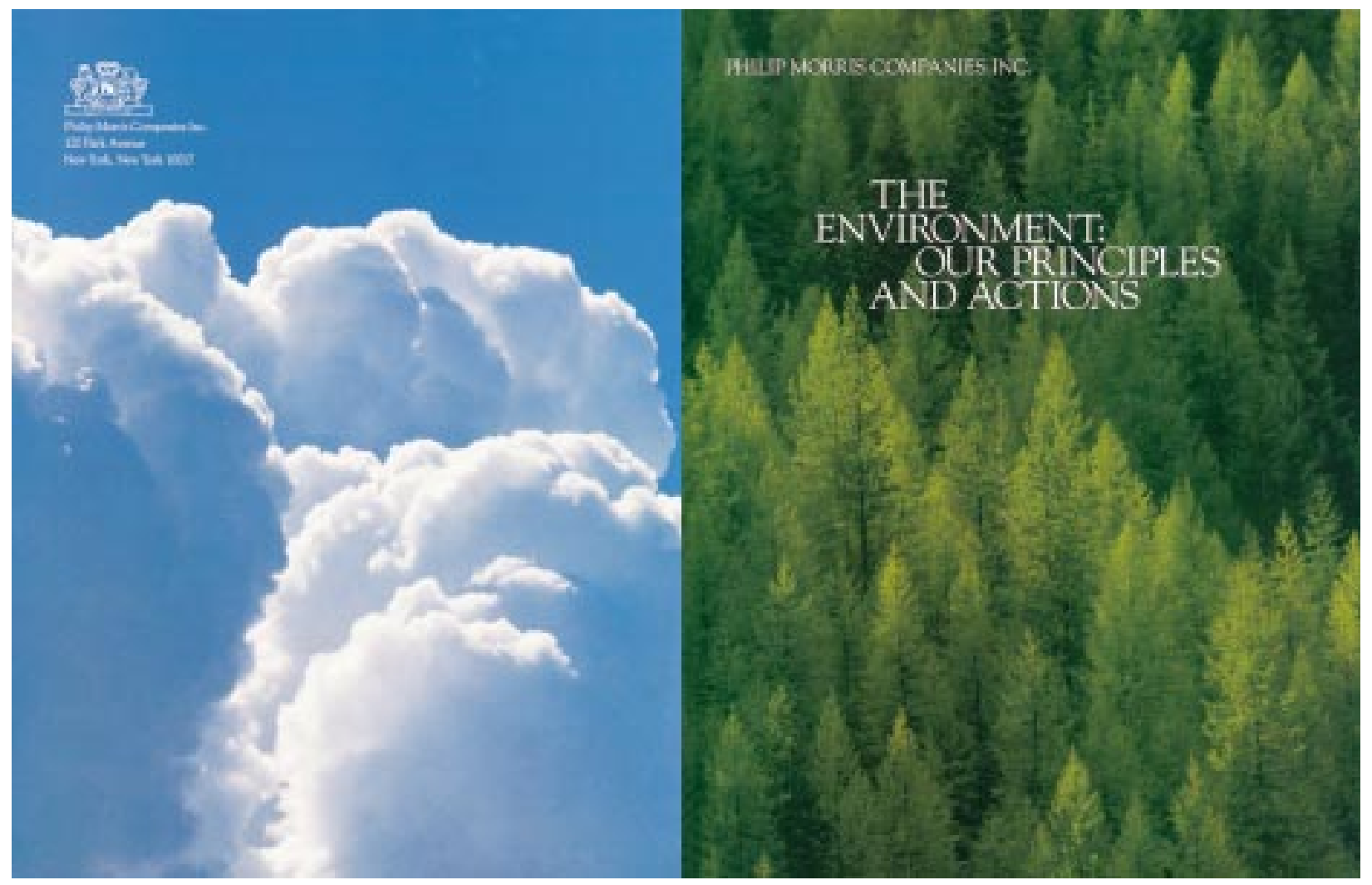

A Philip Morris publication, describing the company's principles and actions to protect our water, air, and land. 